\title{
HUBUNGAN PARENTING STRESS, PENGASUHAN DAN PENYESUAIAN DALAM KELUARGA TERHADAP PERILAKU KEKERASAN ANAK DALAM RUMAH TANGGA
}

\author{
Kinanti Ayu Ratnasari, Kuntoro* \\ *Departemen Biostatistika dan Kependudukan \\ Fakultas Kesehatan Masyarakat Universitas Airlangga \\ E-mail :kinanyuu@gmail.com
}

\begin{abstract}
ABSTRAK
Kasus kekerasan anak di Indonesia terus meningkat dari tahun ke tahun. Salah satu faktor mendasar yang dianggap sebagai penyebab utama adalah kesiapan orang tua dalam mengasuh, mendidik, dan membesarkan anak. Penelitian ini bertujuan untuk mengetahui dan mengidentifikasi parenting stress, pengasuhan dan penyesuaian dalam keluarga terhadap perilaku kekerasan anak dalam rumah tangga. Penelitian ini berupa observasional dengan pendekatan survey. Subyek penelitian berjumlah 18 orang yang terdiri dari 6 orang sampel positif kasus,berasal dari nara pidana Rumah Tahanan Negara Klas I Surabaya dengan riwayat kasus kekerasan anak dalam rumah tangga. Sedangkan 12 orang merupakan sampel negatif kasus yang diteliti berdasarkan kelurahan tempat tinggal responden kasus. Variabel independen penelitian adalah parenting stress dan pengasuhan dan penyesuaian dalam keluarga. Hasil pengujian chi-square dengan tabel 2x3 menunjukkan bahwa variabel parenting stress $(\mathrm{p}=0,001)$, pengasuhan dan penyesuaian dalam keluarga $(\mathrm{p}=0,001)$ memiliki hubungan terhadap perilaku kekerasan anak dalam rumah tangga $(\mathrm{p}<0,05)$. Analisis tersebut membuktikan bahwa parenting stress dan pengasuhan dan penyesuaian dalam keluarga memiliki hubungan perilaku kekerasan anak dalam rumah tangga sehingga perlu adanya pendidikan sebelum menikah mengenai kesehatan reproduksi untuk orang tua terutama pada ibu dan anak, serta pendidikan tentang kewajiban orang tua dalam mendidik, merawat, dan membesarkan anak agar calon orang tua lebih siap untuk menghadapi berbagai persoalan dalam rumah tangga.
\end{abstract}

Kata Kunci: Kekerasan Anak, Parenting Stress, Pengasuhan .

\section{ABSTRACT}

Child abuse cases in Indonesia continues to increase from year to year. The basic factors that are considered as the main causes are the readiness of parents in parenting, educating and raising children.This study aims to determine and identify parenting stress, parenting and family adjustment to the violent behavior of children in the household.This study is observational with survey approach. The subjects included 18 people consisting of 6 samples were positive cases came from Rumah Tahanan Negara Klas I Surabaya with a history of child abuse cases in the household.About 12 sampleswere negative cases studiedd by neighborhood residence caserespondents.The independent variable of research is parenting stress and parenting and family adjustment.The results of chi-square test with $2 \times 3$ table shows that the variable of parenting stress $(p=0.001)$, parenting and family adjustment $(p=0.001)$ have been associated with violent behavior of children in the household $(p<0.05)$. The analysis proves that the parenting stress and parenting and family adjustment have been associated with violent behavior of children in the household so that the need for education before marriage about reproductive health for parents, especially 
mothers and children, as well as education about the obligation of parents to educate, care for and raise children that prospective parents be better prepared to face various problems in the household.

Keywords : Child Abuse, Parenting Stress, Parenting.

\section{PENDAHULUAN}

Pertumbuhan penduduk kian meningkat setiap tahunnya di Indonesia. Jumlah penduduk yang semakin padat membuat kebutuhan akan daya pangan, sandang, dan papan juga meningkat. Dalam hal ini dapat dikatakan bahwa Indonesia saat ini sedang mengalami ledakan penduduk di usia muda.

Status dan kondisi anak Indonesia adalah paradoks. Anak merupakan pewaris dan pelanjut masa depan bangsa. Anak adalah tunas, potensi dan generasi penerus cita-cita bangsa, memiliki peran strategis dalam menjamin eksistensi bangsa dan negara di masa mendatang. Situasi anak Indonesia kian hari terus memburuk. Dunia anak yang seharusnya diwarnai dengan kasih sayang orang tua, kegiatan bermain, belajar, dan mengembangkan minat serta bakatnya untuk masa depan, realitasnya diwarnai data kelam dan menyedihkan. Anak Indonesia masih dan terus mengalami kekerasan (Suharto, 2003).

Kekerasan sebagai perilaku yang tidak layak yang mengakibatkan kerugian atau bahaya secara fisik, psikologis, atau finansial, baik yang dialami individu maupun kelompok (Huraerah, 2012).

Kekerasan terhadap anak seringkali diidentifikasikan sebagai kekerasan kasat mata, seperti kekerasan fisikal dan seksual. Padahal, kekerasan yang bersifat psikis dan sosial (struktural) juga membawa dampak buruk dan permanen pada anak (Huraerah, 2012).

(Huraerah, 2012) mengemukakan bahwa beberapa karakteristik kekerasan dalam rumah tangga sebagai berikut. Pertama, semua bentuk kekerasan dalam keluarga menyangkut penyalahgunaan kekuatan. Pola yang umum terjadi adalah disalahgunakannya kekuatan oleh yang paling kuat terhadap yang paling lemah. Kedua, adanya tingkat kekerasan, dari yang ringan sampai sangat berat atau fatal. Ketiga, kekerasan dilakukan berkali-kali. Keempat, kekerasan dalam keluarga atau rumah tangga umunya berlangsung dalam konteks penyalahgunaan dan eksploitasi psikologis (kekerasan verbal). Terakhir, kekerasan dalam keluarga atau rumah tangga menpunyai dampak negatif terhadap semua anggota keluarga atau rumah tangga, baik yang terlibat dalam kekerasan maupun tidak. 
Undang Undang Nomor 35 Tahun 2014 tentang Perubahan Atas UndangUndang Nomor 23 Tahun 2002 tentang Perlindungan Anak Pasal 15 bahwasannya setiap anak berhak memperoleh perlindungan dari penyalahgunaan dalam kegiatan politik, pelibatan dalam sengketa bersenjata, pelibatan dalam kerusuhan sosial, pelibatan dalam peristiwa yang mengandung unsur kekerasan, pelibatan dalam peperangan dan kejahatan seksual. Dan Pasal 20 yang mengamanatkan bahwa Negara, Pemerintah, Pemerintah Daerah, Masyarakat, Keluarga, dan Orang tua atau Wali berkewajiban dan bertanggung jawab terhadap penyelenggaraan perlindungan anak.

Menurut Bina Kesehatan Anak dan UNICEF (2007) kekerasan terhadap anak terdiri dari faktor sosioekonomi, faktor orang tua, dan faktor anak. Faktor orang tua memegang peranan penting terjadinya perilaku kekerasan terhadap anak. Latar belakang orang tua mengalami kekerasan, gangguan emosional (belum mencapai kematangan emosi, stress, depresi, dan sebagainya), serta pengaruh NAPZA dan minuman keras.

Keluarga merupakan fondasi primer bagi perkembangan kepribadian dan tingkah laku anak. Keberhasilan keluarga atau orang tua dalam membentuk watak anak sangat bergantung pada subyek-subyek dalam keluarga tersebut.
Ketidaktahuan orang tua dalam mendidik dan mengasuh anak dengan baik dapat mengakibatkan anak tumbuh dengan pribadi yang lemah dan merasa kesulitan dalam bersosialisasi di masyarakat. Pada konteks kekinian, terjadinya kekerasan terhadap anak dalam keluarga, sebagai pangkal penyebabnya adalah rapuhnya tatanan keluarga.

Parenting stress dan pengasuhan dan penyesuaian dalam keluarga. Perenting stress timbul ketika orang tua mengalami kesulitan dalam memenuhi tuntutan menjadi orang tua dan hal tersebut mempengaruhi perilaku, kesejahteraan, dan penyesuaian diri pada anak (Berry \& Jones, 1995).

Pengasuhan dan penyesuaian dalam keluarga merupakan sebuah penelitian yang telah diuji mengenai karakteristik psikometrik. Dikemas untuk menilai perubahan dalam praktik pola asuh orang tua dan penyesuaian orang tua dalam evaluasi kesehatan masyarakat dan individu atau intervensi kelompok orang tua. Dalam pengasuhan dan penyesuaian dalam keluarga terdapat 7 indikator untuk mengukur praktik pola asuh orang tua dan kualitas hubungan orang tua dengan anak dan dari skala penyesuaian keluarga yang mengukur tingkat emosional orang tua beserta pasangannya serta dukungan keluarga dalam mengasuh anak (Sanders, et. al., 2013) 
Komisi Perlindungan Anak Indonesia (KPAI) menyebutkan bahwa kasus kekerasan terhadap anak setiap tahun selalu meningkat. Data dari 2011 hingga 2014 mencatat tingkat peningkatan kasus kekerasan pada anak yang signifikan, yakni dengan rincian 2011 sebanyak 2178 kasus, 2012 berjumlah 3512 kasus, 2013 bejumlah 4311 kasus, dan 2014 sebanyak 5066 kasus.

Kasus kekerasan anak yang ditangani oleh Pusat Pelayanan Terpadu (PPT) Perempuan dan Anak Korban Kekerasan Provinsi Jawa Timur tahun 2015 berjumlah 77 kasus. Jenis kekerasan terbesar adalah kekerasan secara psikisdengan jumlah 37 kasus. Sedangkan sebanyak 51 kasus kekerasan dialami oleh anak perempuan. Kekerasan anak sering disebut dengan kekerasan kasat mata seperti kekerasan fisik dan seksual. Padahal kekerasan psikis dan sosial (penelantaran) juga menimbulkan dampak yang buruk bagi kondisi psikologis anak. Disamping itu, anak perempuan lebih rentan dibandingkan dengan anak laki-laki sehingga sering menjadi korban kekerasan.Anak perempuan juga beresiko mengalami kekerasan seksual, sebab mereka belum memiliki pengetahuan yang cukup mengenai kesehatan resproduksi serta bagian tubuh mana saja yang berharga dan tidak boleh disentuh oleh orang laun.
Data dari Polrestabes Surabaya mengenai kasus kekerasan anak menunjukkan pada tahun 2011 terjadi 58 kasus. Tahun 2012 terjadi peningkatan sebanyak 70 kasus, tahun 2013 terdapat 76 kasus, tahun 2014 berjumlah 75 kasus, tahun 2015 sebanyak 60 kasus, dan pada tahun 2016 sampai dengan bulan April sudah terdapat 28 kasus.

\section{METODE PENELITIAN}

Penelitian ini merupakan penelitian observasional, yaitu penelitian yang hanya melakukan pengamatan dan tidak memberikan perlakuan atau intervensi kepada subyek yang diteliti. Desain penelitian menggunakan pendekatan survey, yaitu penyelidikan yang diadakan untuk memperoleh fakta-fakta dari gejala yang ada dan mencari keterangan secara faktual. Pendekatan survey juga menerangkan hubungan, menguji hipotesis, membuat prediksi serta mendapatkan makna dan implikasi dari suatu masalah yang ingin dipecahkan (Moh. Nazir, 2005).

Responden penelitian adalah responden dengan riwayat melakukan kekerasan anak dalam rumah tangga, yang seluruhnya diambil dari Rumah Tahana Klas I Surabaya. Sedangkan responden kedua adalah responden yang tidak memiliki riwayat kekerasan anak dalam rumah tangga, yakni warga yang bertempat tinggal satu Kelurahan dengan tempat 
tinggal nara pidana. Besar sampel mengacu pada rumus Slovin (2006) dengan total sampel sebesar 18 orang. Jumlah perbandingan antara responden positif kasus dengan responden negatif kasus sebesar dua kali lipat responden positif kasus, yakni $1: 2$.

Penelitian dilakukan di Rumah Tahanan Negara Klas I Surabaya dan keluraan tempat tinggal responden positif kasus pada tanggal 20 Mei sampai dengan 29 Juni 2016. Variabel penelitian terdiri dari variabel dependen dan independen.Variabel tersebut dapat dilihat pada kerangka penelitian berikut ini.

Gambar 1. Kerangka Variabel Penelitian

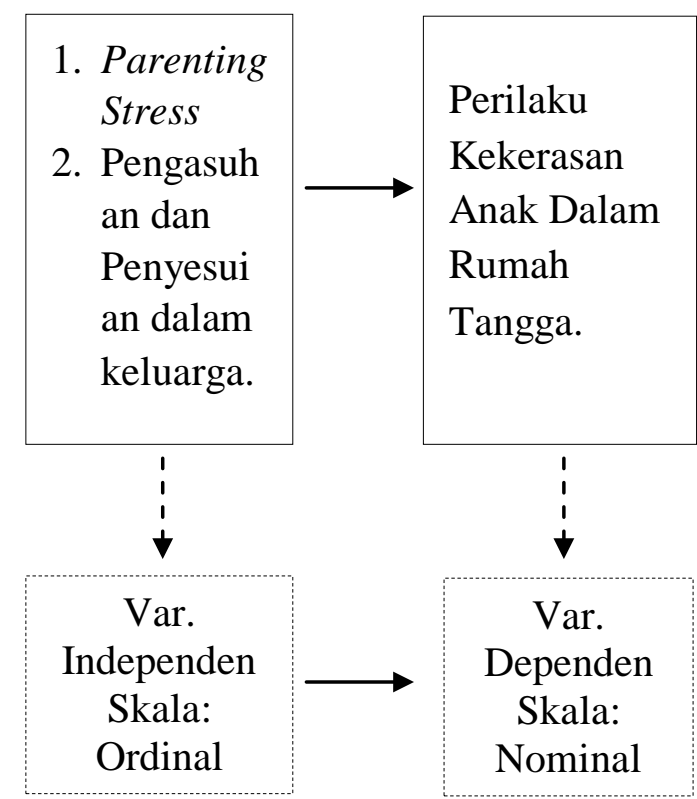

Data dalam penelitian ini merupakan data primer yang diambil dengan pengisian lembar kuisioner dari responden. Alat ukur penelitian adalah kuisioner Berry dan Jones, The Parental Stress Scale. (1995) dan Parenting and Family Adjustment
Scale (PAFAS) oleh Sanders, et. al.(2013). Pada penelitian ini juga diperoleh data sekunder dari Polrestabes Surabaya, Pusat Pelayanan Terpadu (PPT) Perempuan dan Anak Korban Kekerasan Provinsi Jawa Timur dan Rumah Tahanan Negara Kelas I Surabaya. Data tersebut digunakan untuk mempertajam analisis kasus.

Analisis data dilakukan secara deskriptif dan analitik. Analisis deskriptif bertujuan untuk memberikan gambaran variabel yang diteliti, sedangkan analisis analitik digunakan dalam pengolahan data dengan melakukan analisis terhadap sampel penelitian untuk mengetahui hubungan antar variabel dengan menggunakan uji statistik chi-square.

\section{HASIL PENELITIAN}

Sampel penelitian dibagi menjadi 2, yakni sampel positif kasus dan sampel negatif kasus. Sampel positif kasus berjumlah 6 orang yang merupakan nara pidana Rumah Tahanan Negara Klas I Surabaya. Sampel tersebut merupakan responden yang memiliki riwayat kasus kekerasan terhadap anak dalam rumah tangga dan telah diadili secara hukum.

Sampel negatif kasus berjumlah 12 orang merupakan sampel kontrol, yakni warga yang tinggal satu Kelurahan dengan sampel positif kasus dan tidak memiliki riwayat kekerasan. Hasil survey menunjukkan bahwa terdapat 5 keluraha di Surabaya, yakni Kelurahan Kenjeran, 
Kelurahan Siwalankerto, Kelurahan Bratajaya, Kelurahan Wonorejo dan Kelurahan Bulak Banteng. Masing-masing dari kelurahan tersebut ddiambil 2 sampel kontrol, kecuali untuk Kelurahan Bulak Banteng diambil sebanyak 4 orang sampel dikarenakan terdapat 2 nara pidana yang bertempat tinggal di wilayah yang sama.

Tabel1. Distribusi Responden Berdasarkan Tingkat Parenting Stress di Surabaya Tahun 2016.

\begin{tabular}{lcc}
\hline $\begin{array}{c}\text { Tingkat } \\
\text { Stress }\end{array}$ & Frekuensi & $\begin{array}{c}\text { Persentase } \\
(\mathbf{\%})\end{array}$ \\
\hline Ringan & 11 & 61,11 \\
\hline Sedang & 3 & 16,67 \\
\hline Berat & 4 & 22,22 \\
\hline \multicolumn{1}{c}{ Total } & 18 & 100
\end{tabular}

Tabel 1 menunjukkan bahwa tingkat perenting stress yang dialami responden paling tinggi berada pada kategori ringan dengan persentase sebesar 61,11\%, sedangkan kategori yang paling rendah dialami responden berada pada kategori sedang, yakni sebesar 16,67\%.

Tabel 2.Distribusi Responden Tingkat Pengasuhan dan Penyeuaian dalam Keluarga di Surabaya Tahun 2016.

\begin{tabular}{lcc}
\hline $\begin{array}{c}\text { Tingkat } \\
\text { Pengasuhan } \\
\text { dan } \\
\begin{array}{c}\text { Penyesuaian } \\
\text { dalam Keluarga }\end{array}\end{array}$ & $\begin{array}{c}\text { Freku- } \\
\text { ensi }\end{array}$ & $\begin{array}{c}\text { Persent- } \\
\text { ase (\%) }\end{array}$ \\
\hline Kurang & 2 & 11,11 \\
\hline Sedang & 3 & 16,67 \\
\hline Baik & 13 & 72,22 \\
\hline \multicolumn{1}{c}{ Total } & 18 & 100
\end{tabular}

Tabel 2 menunjukkan bahwa responden dengan persentase terbesar berada pada kategori pengasuhan dan penyesuaian dalam keluarga yang baik, yakni sebesar $72,22 \%$ dan responden dengan persentase terkecil berada pada kategori pengasuhan dan penyesuaian dalam keluarga yang kurang, yakni sebesar 11,11\%..

Berikut adalah analisis deskriptif dengan tabel tabulasi silang antara perilaaku kekerasan anak dalam rumah tangga terhadap parenting stress dan pengasuhan dan penyesuaian dalam keluarga.

Tabel 3. Tabulasi Silang Perilaku Kekerasan Anak dalam Rumah Tangga terhadap Parenting Stress di Surabaya Tahun 2016.

\begin{tabular}{ccccccc}
\hline Parenti- & \multicolumn{3}{c}{ Perilaku } & \multicolumn{2}{c}{ Total } \\
ng & \multicolumn{3}{c}{ Kekerasan Anak } & & \\
Stress & Ya & $\%$ & Ti & $\%$ & N & $\%$ \\
& & & $\begin{array}{c}\text { da } \\
\text { k }\end{array}$ & & & \\
& & & & & \\
& & & & &
\end{tabular}

\begin{tabular}{lcccccc}
\hline Ringan & 0 & 0 & 11 & 91,7 & 11 & 61,1 \\
\hline Sedang & 2 & 33,3 & 1 & 8,3 & 3 & 16,7 \\
\hline Berat & 4 & 66,7 & 0 & 0 & 4 & 22,2 \\
\hline \multicolumn{1}{c}{ Total } & 6 & 100 & 12 & 100 & 18 & 100
\end{tabular}

Responden yang dinyatakan mengalami parenting stress dalam kategori berat sebanyak 4 orang responden (66,7\%) yang seluruhnya adalah responden yang melakukan kekerasan anak, sedangkan responden yang mengalami parenting stress dalam kategori ringan sebesar 11 orang responden (91,7\%) yang tidak melakukan kekerasan anak. 
Tabel 4. Distribusi Perilaku Kekerasan Anak dalam Rumah Tangga terhadap Pengasuhan dan Penyesuaian dalam Keluarga di Surabaya Tahun 2016.

\begin{tabular}{|c|c|c|c|c|c|c|}
\hline \multirow{2}{*}{$\begin{array}{c}\text { Pengasu- } \\
\text { han dan } \\
\text { Penyesu- } \\
\text { aian } \\
\text { dalam } \\
\text { Keluarga }\end{array}$} & \multicolumn{4}{|c|}{$\begin{array}{c}\text { Perilaku Kekerasan } \\
\text { Anak }\end{array}$} & \multicolumn{2}{|c|}{ Total } \\
\hline & Ya & $\%$ & $\begin{array}{c}\text { Tida } \\
\mathbf{k}\end{array}$ & $\%$ & $\mathbf{N}$ & $\%$ \\
\hline Kurang & 2 & 33,3 & 0 & 0 & 2 & 11,1 \\
\hline Sedan & 3 & 50 & 0 & & 3 & 16,7 \\
\hline Baik & 1 & 16,7 & 12 & 100 & 13 & 72,2 \\
\hline Total & 6 & 100 & 12 & 100 & 18 & 100 \\
\hline
\end{tabular}

Responden yang melakukan perilaku kekerasan anak terbanyak mengalami pengasuhan dan penyesuaian dalam keluarga dalam tingkat sedang, yakni sebanyak 3 orang (50\%), sedangkan responden yang tidak melakukan perilaku kekerasan seluruhnya mengalami pengasuhan dan penyesuaian dalam keluarga berada pada kategori baik, yakni sebesar 12 orang (100\%).

Berikut ini adalah tabel hasil uji chi square.

Tabel 5.Hasil Uji Chi-Square Perilaku Kekerasan Anak dalam Rumah Tangga dengan Parenting Stress.

\begin{tabular}{|c|c|c|c|}
\hline & Value & df & Sig. \\
\hline $\begin{array}{l}\text { Pearson } \\
\text { Chi-square }\end{array}$ & 15,000 & 2 & 0,001 \\
\hline Likelihood ratio & 19,095 & 2 & 0,000 \\
\hline $\begin{array}{l}\text { Linear-by-linear } \\
\text { Association }\end{array}$ & 13,885 & 1 & 0,000 \\
\hline $\mathrm{N}$ of Valid Cases & 18 & & \\
\hline
\end{tabular}

Berdasarkan hasil uji chi-square pada tabel 5 menunjukkan bahwa variabel parenting stress memiliki nilai $\mathrm{p}_{\text {value }}(0,001)<\alpha$ $(0,05)$. Jika memiliki nilai $\mathrm{p}_{\text {value }}$ kurang dari $\alpha(0,05)$, maka variabel independen dikatakan signifikan atau memiliki hubungan.

Tabel 6. Hasil Uji Chi-Square Perilaku Kekerasan Anak dalam Rumah Tangga dengan Pengasuhan dan Penyesuaian dalam Keluarga. Value df Sig.

\begin{tabular}{lccc}
\hline $\begin{array}{l}\text { Pearson } \\
\text { Chi-square }\end{array}$ & 13,846 & 2 & 0,001 \\
\hline Likelihood ratio & 15,864 & 2 & 0,000 \\
\hline $\begin{array}{l}\text { Linear-by-linear } \\
\text { Association }\end{array}$ & 11,181 & 1 & 0,001 \\
\hline
\end{tabular}

$\mathbf{N}$ of Valid Cases 18

Berdasarkan hasil uji chi-square pada tabel 6 menunjukkan bahwa variabel pengasuhan dan peyesuaian dalam keluarga memiliki nilai $\mathrm{p}_{\text {value }}(0,001)<\alpha$ $(0,05)$. Jika memiliki nilai $\mathrm{p}_{\text {value }}$ kurang dari $\alpha(0,05)$, maka variabel independen dikatakan signifikan atau memiliki hubungan.

\section{PEMBAHASAN}

Pada proses pengambilan data, terdapat kesulitan dalam hal menemukan sampel positif kasus. Hal ini dikarenakan banyak diantara kasus kekerasan dalam rumah tangga yang telah mencapai pengadilan mendapatkan putusan damai, sebab kedua belah keluarga tidak ingin menanggung malu. Akhirnya pada penelitian ini sampel positif kasus ditemukan di Rumah Tahanan Negara Klas I Surabaya. 
Hubungan Perilaku Kekerasan Anak dalam Rumah Tangga dengan Parenting Sress.

Parenting stress dalam penelitian ini adalah stress atau kondisi psikologis yang dialami oleh ayah dalam mengurus anak dan rumah tangganya. Sumber stress berasal dari individu ayah, kondisi keluarga, hubungan ayah dengan anak. Rusmil (dalam Huraerah, 2012) menjelaskanorang tua yang dibesarkan dengan latar belakang penganiayaan, gangguan mental (stress, depresi dan sebagainya) memiliki kecenderungan untuk melakukan tindak kekerasan terhadap anak. Seperti halnya yang dikemukakan oleh Suharto (1997) penyakit parah atau gangguan mental pada salah satu kedua orang tua, misalnya tidak mampu merawat dan mengasuh anak karena gangguan emosional dan depresi. Menurut Zigler dan Hall (dalam Mutiah, 2015) mengemukakan perspektif teori bahwa orang tua yang melakukan kekerasan terhadap anak dianggap menderita gangguan jiwa seperti psikopat atau sosiopat.

Hasil uji chi-square pada tabel 5 menunjukkan bahwa nilai $\mathrm{p}_{\text {value }}(0,001)<\alpha$ $(0,05)$. Artinya parenting stress memiliki hubungan dengan perilaku kekerasan anak dalam rumah tangga. Hasil tersebut sesuai dengan beberapa teori yang dikemukakan sebelumnya. Seperti yang ditunjunjukkan dalam tabel 3 bahwa sebesar 66,7\% responden positif kasus mengalami parenting stress pada kategori berat.

Berry \& Jones (1995) menyatakan bahwa orang tua yang mengalami parenting stress akan menunjukkan sikap tidak memberi dukungan, mudah tersinggung, dan hanya sedikit memberi kasih sayang kepada anaknya. Selain itu, mereka juga akan menjadi bersikap kasar, kritis, dan kaku dalam menghadapi anaknya.

Berdasarkan penelitian Yuliawati (2008) pada 72 responden menunjukkan adanya hubungan tingkat stress orang tua dengan perilaku kekerasan verbal terhadap anak. Sebuah penelitian pada 90 responden oleh Nugrahani (2015) menunjukkan bahwa parenting stress memiliki hubungan yang positif dengan kecenderungan perilaku kekerasan terhadap anak.

Hubungan Perilaku Kekerasan Anak dalam Rumah Tangga dengan Pengasuhan dan Penyesuaian dalam Keluarga

Keluarga merupakan fondasi primer bagi perkembangan, kepribadian, dan tingkah laku anak (Huraerah, 2012). Pengasuhan dan penyesuaian dalam keluarga merupakan sebuah alat ukur yang menilai kemampuan orang tua dalam mengasuh anak, hubungan dalam keluarga baik orang tua dengan anak, dengan pasangannya, dan anggota keluarga yang baik (Sanders, et al., 2013). 
Sanders, et al (2013) mengunkapkan bahwa dalam pengasuhan dan penyesuaian dalam keluarga terdapat 7 unsur penilaian, yakni parental consistency, coercive parenting, positive encouragement, parent-child relationship, parental adjustment, family relationship, dan parental teamwork. Dalam hal ini, kekerasan terhadap anak terjadi dikarenakan misfunction dalam keluarga, keluarga yang kurang dalam memahami dan menerapkan ketujuh aspek di atas akan menjadikan kekerasan sebagai bentuk konsekuensi yang logis terhadap anak.

Hasil uji chi-square pada tabel 6 menunjukkan bahwa variabel pengasuhan dan peyesuaian dalam keluarga memiliki nilai $\mathrm{p}_{\text {value }}(0,001)<\alpha(0,05)$. Artinya pengasuhan dan penyesuaian dalam keluarga memiliki hubungan dengan perilaku kekerasan anak dalam rumah tangga. Hal tersebut seperti yang terpapar dalam tabel 4 yang menunjukkan bahwa sebesar 33,3\% responden positif kasus dinyatakan kurang dalam proses pengasuhan dan penyesuaian dalam keluarga.

Berdasarkan penelitian Fataruba (2009) pada 187 sampel menunjukkan bahwa terdapat hubungan yang bermakna antara pola asuh orang tua terhadap perilaku kekerasan terhadap anak usia sekolah (6-18 tahun). Menurut Puspitawati, et al. (2011) pada 35 anak dari 56 anak korban kekerasan periode 2007-2009 berdasarkan data dari kepolisian Bogor menunjukkan bahwa ada hubungan negatif antara kekerasan pada anak dengan hubungan orang tua dan anak. Hal ini menunjukkan apabila semakin tinggi hubungan kehangatan orang tua dengan anak, maka semakin rendah perilaku kekerasan terhadap anak. Disamping itu, $14,3 \%$ anak dalam penelitian tersebut mengalami permasalahan keluarga dalam kategori tinggi.

\section{SIMPULAN DAN SARAN}

Berikut adalah simpulan dan saran yang diperoleh dari hasil penelitian.

\section{Simpulan}

Parenting stress memiliki hubungan dengan perilaku kekerasan anak dalam rumah tangga. Artinya semakin tinggi tingkat parenting stress yang dialami orang tua, kemungkinan lebih besar melakukan perilaku kekerasan anak dalam rumah tangga dibandingkan dengan orang tua yang mengalami tingkat parenting stress ringan.

Pengasuhan dan penyesuaian dalam keluarga memiliki hubungan dengan perilaku kekerasan anak dalam rumah tangga. Artinya Responden yang memiliki nilai baik pada pengasuhan dan penyesuaian dalam keluarga, kemungkinan lebih kecil untuk melakukan perilaku 
kekerasan terhadap anak dalam rumah tangga dibandingkan dengan responden yang memiliki nilai kurang pada pengasuhan dan penyesuaian dalam keluarga.

\section{Saran}

Upaya preventif bagi kaum muda yang nantinya akan menjadi orang tua, sebaiknya diadakan pendidikan sebelum pernnikahan. Hal ini agar nantinya orang tua ebih siap untuk menjadi orang tua yang bak, mampu secara fsik, psikis, sosial dan materi untuk berkeluarga dan membesarkan anak, mengerti tentang tanggung jawab terhadap anak.

Konseling atau pergi ke psikiater seharusnya bukan hal yang tabu lagi, sebab kesehatan harus mencakup segala aspek baik fisik, psikis, dan sosial. Tentunya ddengan berbagi cerita orang tua mampu untuk lebih terbuka mengenai masalah rumah tangganya. Komunikasi antar anggota keluarga sangat diperlukan untuk mencegah ledakan emosisonal yang dapat mengarah kepada kekerasan dalam rumah tangga. Keluarga merupakan orang terdekat, jadi sebaiknya kita juga perlu mencoba berbicara, memahami dari hati ke hati agar ruma tangga menjadi tempat yang aman dan nyaman bagi anggota keluarga yang lain.

Bagi Rumah Tahanan Negara Klas I Surabaya ssebaiknya dapat menindaklanjuti hasil penelitian. Diketahui bahwa parenting stress dan pengasuhan dan penyesuaian dalam keluarga memiliki hubungan terhadap perilaku kekerasan anak dalam rumah tangga. Upaya yang dapat dilakukan adalah membuat kegiatan yang bersifat mengurangi beban stress nara pidana kasus kekerasan anak dalam rumah tangga seperti konseling, mengontrol jadwal kunjungan keluarga nara pidana, membuat karya seni berupa produk daur ulang, pengajian bersama, dan sebagainya

\section{DAFTAR PUSTAKA}

Akramaniyah, 2015. Kekerasan Terhadap Anak Dalam Lingkup Kekerasan Dalam Rumah Tangga. Skripsi. Universitas Airlangga.

Berry, JD. dan Jones, W.H., 1995. The Parental Stress Scale: Initial Psychometric Evidence. Journal of Social and Personal Relationship. Vol 12, pp. 463-472.

Bert, S. C., Bella M. G., dan Robin G. L., 2009. The Influence of Maternal History of Abuse on Parenting Knowledge and Behavior. ProQuest Nursing \& Allied Health Source. Vol 58 (2), pp. 176-187.

Bina Kesehatan Anak dan UNICEF., 2007. Pedoman Rujukan Kasus Kekerasan Terhadap Anak Bagi Petugas Kesehatan. http://id.scribd.com/mobile/doc/13295 3725/Pedoman-Rujukan-KasusKekerasan-terhadap-anak-BagiPetugas-Kesehatan. [15 Oktober 2015].

Fataruba, R., Purwatiningsih, S., Wardani, Y., 2009. Hubungan Pola Asuh Dengan Kejadian Kekerasan Terhadap Anak Usia Sekolah (6-18 Tahun) di Kelurahan Dufa-Dufa Kecamatan Ternate Utara. KES MAS. Vol 3 (3) pp. 168-173. 
Huraerah, A., 2012. Kekerasan Terhadap Anak Edisi Ketiga. Bandung: Nuansa Cendekia.

Kaltner, M., 2013. Re-referral for Complex Child Abuse and Neglect Concerns: The Influence of Family and Child Factors in a 25 Year Data Set. Children Australia. Vol.38 (1), pp. 15-21.

Kuntoro, H., 2007. Metode Statistik. Surabaya: Pustaka Melati Surabaya.

Kuntoro, H., 2009. Dasar Filosofis Metodologi Penelitian. Surabaya: Pustaka Melati.

KPAI, 2014.Pelaku Kekerasab Terhadap Anak Tiap Tahun Meningkat. http://www.kpai.go.id/berita/kpaipelaku-kekerasan-terhadap-anaktiap-tahunmeningkat/ [19 September 2015].

Manurung, S. M., 2015. Faktor-Faktor Yang Mempengaruhi Tindakan Kekerasan Anak Dalam Keluarga. Skripsi. Universitas Sumatera Utara.

Moh. Nazir., 2005. Metode Penelitian. Bogor: Ghalia Indonesia.

Mutiah, D., 2015. Faktor-Faktor yang Mempengaruhi Kekerasan terhadap Anak. Skripsi. Universitas Islam Negeri Syarif Hidayatullah.

Nugrahani, S., 2015. Hubungan Parenting Stress Dengan Kecenderungan Perilaku Kekerasan Terhadap Anak. Skripsi. Universitas Negeri Semarang.

Puspitawati, H., Djamaludin, M. D., Nursanti, H., 2009. Kekerasan, Kondisi Keluarga, dan Kesejahteraan Keluarga Pada Anak Korban Kekerasan. Jur. Ilm. Kel. \& Kons. Vol 4 (2) pp. 130-138.

Sanders, M. R., Morawska, A., Haslam, D. M., Filus, A., Fletcher, R., 2013. Parenting and Family Adjustment Scales (PAFAS): Validation of a Brief Parent-Report Measure for Use in Assessment of Parenting Skill and Family Relationship. Chi;d Psychiatry Hum Dev. DOI 10.1007/s10578-013-0397-3, Vol 45 pp. 255-272.

Stuart dan Sundeen, 2006., Buku Saku Keperawatan Jiwa, ed 3. Jakarta: EGC.

Suharto, E., 1997. Pembangunan, Kebijakan Sosial, dan Pekerjaan Sosial. Bangdung: Lembaga Studi PembangunanSekolah Tinggi Kesejahteraan Sosial.

Suharto, E., 2003. Pendekatan Pekerjaan Sosial dalam Mengatasi Masalah Anak. Makalah Disampaikan pada Seminar Internasional Penanggulangan Masalah Anak. Eradication Child Problems: Policy, Program, and Strategy,tanggal 5 Juli 2003 di Wisma Buana Kampus UNLA Bandung.

Sugiyono, 2006. Statistik Untuk Penelitian Cetakan Ketujuh. Bandung: CV, Alfabeta.

Undang Undang Republik Indonesia Nomor 23 Tahun 2002 tentang Perlindungan Anak.

Undang Undang Republik Indonesia Nomor 35 tahun 2014 tentang Perubahan Atas UU No 23 Tahun 2002 tentang Perlindungan Anak.

Yuliawati, A., 2008. Hubungan Tingkat Stress Orang tua dengan Perilaku Kekerasan Verbal pada Anak di Kelurahan Jabungan Kecamatan Banyumanik Kota Semarang. Skripsi. Universitas Diponegoro. ejournal.undip.ac.id/article/download. [4Juli 2016]. 